\title{
Examination of the profitability of technical analysis based on moving average strategies in BRICS
}

\author{
Matheus José Silva de Souza', Danilo Guimarães Franco Ramos², Marina Garcia Pena², \\ Vinicius Amorim Sobreiro ${ }^{2^{*}}$ and Herbert Kimura ${ }^{2}$
}

\footnotetext{
* Correspondence: sobreiro@unb.br

${ }^{2}$ Department of Management,

University of Brasília, Federal District, Brazil

Full list of author information is

available at the end of the article
}

\begin{abstract}
In this paper, we investigated the profitability of technical analysis as applied to the stock markets of the BRICS member nations. In addition, we searched for evidence that technical analysis and fundamental analysis can complement each other in these markets. To implement this research, we created a comprehensive portfolio containing the assets traded in the markets of each BRICS member. We developed an automated trading system that simulated transactions in this portfolio using technical analysis techniques. Our assessment updated the findings of previous research by including more recent data and adding South Africa, the latest member included in BRICS. Our results showed that the returns obtained by the automated system, on average, exceeded the value invested. There were groups of assets from each country that performed well above the portfolio average, surpassing the returns obtained using a buy and hold strategy. The returns from the sample portfolio were very strong in Russia and India. We also found that technical analysis can help fundamental analysis identify the most dynamic companies in the stock market.
\end{abstract}

Keywords: Technical analysis, Moving average strategies, Automated trading systems, Portfolio analysis, BRICS

\section{Introduction}

The basic principle of technical analysis (TA) is that patterns related to past prices of instruments traded in the asset markets can be used to predict the direction of future prices. The objective is to enhance the return of an investment portfolio by understanding the interaction of price indicators for the portfolio's holdings over an identified time period. According to Stanković et al. (2015), TA is a way of detecting trends in asset prices based on the premise that the price series moves according to investors' perceived standards. Their study demonstrated that the duration of these standards is sufficient for the investor to make above-average profits, even if the investments incur transaction costs.

The goal of our research was to investigate the profitability of trading strategies based on TA in the stock markets of BRICS countries. To this end, we developed an automated trading system based on the moving averages of past prices. We demonstrated that this trading system, using technical analysis techniques, could

(c) The Author(s). 2018 Open Access This article is distributed under the terms of the Creative Commons Attribution 4.0 International License (http://creativecommons.org/licenses/by/4.0/), which permits unrestricted use, distribution, and reproduction in any medium, provided you give appropriate credit to the original author(s) and the source, provide a link to the Creative Commons license, and indicate if changes were made. 
surpass the profitability of a buy and hold strategy for a portion of the traded assets, calculated by country. The work presented in this paper updated the findings of previous research, and found that technical analysis can help fundamental analysis identify the most dynamic companies in the stock market.

TA uses a systematic, graphical approach to identify patterns of historical trading prices and market movements, and then formulate predictions that may generate abnormally strong returns. According to Murphy (1999, pp. 1-2), graphs are the primary instruments of TA. The graphs reflect indicators, such as moving averages and oscillators, that allow analysts to detect trends, identify points of inflection in the price movement, and track capital inflows and outflows.

The tools used by TA can provide an index of resistance and support as well. Indicators include the Relative Strength Index (RSI), the Moving Average Convergence Divergence (MACD), and the Average Directional Index (ADX), among others. These indicators seek to estimate patterns of future behavior and predict buy and sell opportunities solely from the previously verified pricing of assets. More specifically, Vandewalle et al. (1999, pp. 170-172) defined moving averages as transformations of a price series that allow us to identify trends from data smoothing.

According to Gerritsen (2016), the success of technical analysis trading rules would conflict with the weak form of the Efficient Market Hypothesis (EMH) (Fama 1970), which holds that current asset prices reflect all relevant past data. In its weak form, EMH states that it is not possible to obtain above-average returns from the study of past prices (Malkiel and Fama 1970, p. 383), implying that a price series has a unit root. Therefore, belief in the validity of TA means rejecting EMH. Expressed in economic terms, Jensen (1978, p. 97) considered a market to be efficient if the economic profit is null, i.e., if the market meets the optimal condition that marginal benefit equals the marginal cost of acting based on the publicly available information.

Technical analysis is not compatible with the idea that stock prices can change at random (the random walk hypothesis), as pointed out by Lo and MacKinlay (1987, pp. 87-88). A series of prices presents a unit root, or follows a random walk, if the observations at an instant $t$ can be expressed as the price in $t-1$ added to a random shock. In other words, random factors persist in determining the observations of the variable, since the shock is little dissipated over time. More formally, let $p t$. be the price of an asset at the instant $t$, and let $\varepsilon t$ be a term denoting a random shock. If the data generation process is in the following form:

$$
p_{t}=\alpha \cdot p_{t-1}+\varepsilon_{t}
$$

, then the series of prices is said to be a unit root if $\alpha$ is not statistically different from 1 , which means that the random shock is completely absorbed in the process.

In comparison to TA, fundamental analysis (FA) is focused on the economic and financial aspects of stocks and the markets. According to Lui and Mole (1998), FA turns to the microeconomic aspects of companies and to the macroeconomic fundamentals of sectors and countries - known as market fundamentals (Allen and Taylor 1990) - to justify past movements and to predict 
fluctuations. Through the review of previous research, we also made clear that FA and TA are not mutually exclusive tools for analyzing market data, but rather explore different drivers of price behavior. TA could be an auxiliary tool to FA. In fact, some studies explored a hybrid approach using both TA and FA, e.g., Lui and Mole (1998), Lam (2004), and António Silva and Neves (2015). In this paper, however, we focused primarily on TA. For our research, we assumed that prices are determined by the equilibrium between the supply and demand of the asset to which they refer. Therefore, prices captures any considerations that may be brought by fundamental analysis (Nison 1991, pp. 8-11).

The remainder of this paper is structured as follows: In Section 2, we give a brief summary of related research regarding both the development of TA and the results of experiments with data from emerging countries. Section 3 provides the conceptual foundation of TA, while section 4 explains our method and the algorithm applied to generate buy and sell signals. Section 5 discusses the main results obtained, demonstrates the importance of using TA and FA as complementary tools for obtaining profits in the open market, and draws attention to the importance of these results for the literature. Section 6 provides our conclusion.

\section{Related research}

Scholars have tested the efficiency of the tools of technical analysis frequently, for example, in the studies of Allen and Taylor (1990), Jegadeesh (2000), and Kuang et al. (2014). The main reasons for this continued research, as discussed in Zhu and Zhou (2009), were that previous studies of the profitability of technical analysis obtained inconclusive results and lacked a scientific basis. Consequently, more consistent hypotheses to justify TA were needed. For example, Allen and Taylor (1990), Frankel and Froot (1986), Shiller (1989), and others pointed out the irrationality of TA. According to Allen and Taylor (1990), the subjectivity of this approach prevents it from acquiring a scientific character. Frankel and Froot (1986) and Shiller (1989) held that the use of technical indicators leads to overvaluation of asset prices, thereby heating up the demand for some assets without good reason.

There have been few experimental tests of the profitability of the TA indicators across the typical market structures of emerging countries. In particular, further work is needed regarding the BRICS member nations, a special subgroup composed of Brazil, Russia, India, China, and South Africa. Recently, studies were carried out on isolated emerging markets that are not similar to each other, including contributions by Chang et al. (2004), Kuang et al. (2014), Mitra (2011), and Mobarek et al. (2008). However, none of these studies proposed a comparison of the results for groups of similar countries, so they failed to answer whether TA is profitable for emerging markets as a whole.

Interest in these countries has been stimulated by the typical characteristics of their macroeconomic environments, such as instability, uncertainty, and inflation resulting from their adopted economic growth strategies. According to Chang et al. (2004), emerging countries became attractive markets to investors looking for portfolio diversification and financial returns above the average attainable from the 
consolidated markets of developed countries. Emerging markets differ from markets in developing countries insofar as they are closer to the markets of developed countries, making them more dynamic and attractive to foreign investors. On this topic, Mukherjee and Roy (2016) emphasized the relationship between instrument price fluctuations and macroeconomic particularities.

The good predictability of TA and the high returns in emerging markets are not unanimously accepted in the literature. Chang et al. (2004) and Harvey (1995) emphasized that there is a strong autocorrelation in the price series of emerging markets, which means that the random walk hypothesis is rejected. Therefore, there is a good predictive capacity in these markets. However, Costa et al. (2015) and Ratner and Leal (1999), who considered transaction costs, identified that the predictive capacity of TA does not lead to abnormally strong returns.

In this context, Urrutia (1995) identified positive results of TA for Latin American countries. Noakes and Rajaratnam (2014) signaled mixed results for South Africa because the profitability of TA for low capitalization assets sustains itself, which is the opposite of more commonly traded assets. Sharma and Kennedy (1977) showed negative results for India. Almujamed et al. (2013); Errunza and Losq (1985) suggested there is a lower degree of efficiency in emerging markets, compared to the consolidated markets of developed countries. Sobreiro et al. (2016, p. 99) found that a strategy based on the crossover of moving averages generated greater profits than a static strategy for Russia, Brazil, and Argentina, but not for the markets of Jamaica and China.

Table 1 summarizes the results of the main studies of the profitability of TA in both emerging and developed countries. Surveys were considered to provide mixed evidence if their results demonstrated that the good performance of technical analysis was not sustained after considering transaction costs.

Table 1 Summary of the profitability of TA around the world according to researchers from 1961 to 2016

\begin{tabular}{|c|c|}
\hline Positive Results & Negative Results \\
\hline- & $\begin{array}{l}\text { USA - Alexander (1961), Fama and Blume (1966) } \\
\text { and Brock et al. (1992). }\end{array}$ \\
\hline- & India - Sharma and Kennedy (1977). \\
\hline $\begin{array}{l}\text { Malaysia, Thailand and Taiwan - Bessembinder and } \\
\text { Chan (1995). }\end{array}$ & $\begin{array}{l}\text { Japan and Hong Kong - Bessembinder and } \\
\text { Chan (1995). }\end{array}$ \\
\hline Taiwan - Ratner and Leal (1999). & - \\
\hline Mexico - Ratner and Leal (1999). & - \\
\hline Thailand - Ratner and Leal (1999). & - \\
\hline $\begin{array}{l}\text { Bangladesh, India, Pakistan and Sri Lanka - Gunasekarage } \\
\text { and Power (2001). }\end{array}$ & - \\
\hline Bangladesh - Mobarek et al. (2008). & - \\
\hline- & India - Mitra (2011). \\
\hline- & South Africa - Noakes and Rajaratnam (2014). \\
\hline $\begin{array}{l}\text { USA, Germany and United Kingdom - Cervelló-Royo et al. } \\
\text { (2015). }\end{array}$ & $\begin{array}{l}\text { Singapore, Indonesia and Malaysia - Tharavanij } \\
\text { et al. (2015). }\end{array}$ \\
\hline Russia - Sobreiro et al. (2016). & - \\
\hline Brazil - Sobreiro et al. (2016). & - \\
\hline Argentina - Sobreiro et al. (2016). & - \\
\hline
\end{tabular}


Based on this context, the objective of this paper was to investigate the profitability of moving average trading strategies in the stock markets of BRICS countries. We sought to analyze the performance of TA in environments that are different from those of developed countries and other emerging nations in terms of their stock markets, the behavior of investors, and national economic policies (Mozumder et al. 2015; Naresha et al. 2017).

For this research, we used an automated trading system (ATS) that simulated the transactions based on patterns verified by the data and related to the signals of the moving averages over the prices of the assets. We prepared a comprehensive portfolio for each country, containing all the assets traded in the markets of each BRICS member. For South Africa, China, and India, we included the asset prices from 2000 to 2016. For Brazil and Russia, we used price data from 2007 to 2016. Initial capital transactions were carried out as the model issued buy and sell signals from the interaction of the series of moving averages over prices.

In this work, we sought to complement the approach of Costa et al. (2015) and Sobreiro et al. (2016) in some respects. First, we studied the performance of technical analysis for the instruments traded in Brazil as verified in Costa et al. (2015), and also for the BRICS members, to check the profitability of indicators for a more general class of countries. In contrast to Sobreiro et al. (2016), we included transaction costs, aiming to establish more realistic assumptions.

Our study aimed to update results from Chong et al. (2010) by using more recent data and adding South Africa to the analysis, the latest member to be included in the BRICS countries. In this context, we investigated all BRICS countries, instead of only the BRIC nations, using data through 2016. It is important to highlight that both Sobreiro et al. (2016) and Chong et al. (2010) did not analyze the results of trading strategies that took into account transaction costs. Therefore, our automated trading system, by operating with and without brokerage fees, allowed us to assess the impact of transaction costs on the overall profitability of the strategies.

\section{A brief overview of the conceptual foundation of technical analysis}

Nison (1991, pp. 8-11) added the psychological and emotional components of the rational agents to the study of asset prices in the financial market. This approach was capable of capturing the animal spirits spoken about by Keynes (1936), a concept that is not incorporated in fundamental analysis. Nison (1991) suggested that the study of technical analysis is important because it provides an understanding of why the market moves. The author emphasized that great negotiators make their decisions based on technical indicators. Both the previous price and the influence exercised by leaders over the decisions of other investors are factors that determine the price movement itself.

Ellis and Parbery (2005) highlighted the use of moving averages for the generation of buy and sell signals as a mechanism to identify price trends. While the short-term moving average is more sensitive to price changes, longer term moving averages capture medium- and long-term trends. Investors in the stock exchanges utilize technical analysis extensively, and moving averages are the most 
commonly used indicators because they are simple to understand and relatively easy to use.

Regarding the calculation of the moving averages, let $h$ be the length of the moving average, i.e., the number of observations from which the average of the values will be extracted, and let $N \geq h$ be the position of a given observation from which the previous $h$ values will be included in the calculation of the $N$-th moving average. If SMAN is the $N$-th simple moving average, and $E M A N$ is the $N$ th exponential moving average, they can be calculated as follows:

$$
S M A_{N}=\frac{\sum_{t=N-h+1}^{N} p_{t}}{h}
$$

and

$$
E M A_{N}=\left(\frac{2}{h+1}\right) \cdot p_{t-1}+\left(1+\left(\frac{2}{h+1}\right)\right) \cdot E M A_{N-1}
$$

For a deeper explanation of the simple moving average, please see Vandewalle et al. (1999). According to Appel (2005), the exponential moving average is better than the simple moving average for identifying trends in a price series. Park and Irwin (2007, p. 67) summarized the evidence for the profitability of technical analysis in futures contracts, foreign currency markets, and in the capital markets. According to the authors, from 1988 to 2004, 26 studies obtained positive results for the use of technical indicators in the capital markets, and 12 found negative results. However, Park and Irwin (2007, pp. 29-30) concluded that the positive results of technical analysis were more consistent and significant for the futures and foreign currency markets, compared to results for the stock markets. Also, the authors concluded that TA's positive results for asset markets were subject to data manipulation problems and the creation of ex-post strategies.

In previous research, findings about the profitability of technical analysis were quite inconsistent when applied to the stock markets of emerging countries. In general, the simple moving average (SMA) or exponential moving average (EMA) strategies assured a positive return, but the return was not sustained when transaction costs were considered, such as fees paid to the broker (Brock et al. 1992).

Similar results were presented by Mitra (2011), and Ratner and Leal (1999) when they compared the returns obtained from the generation of buy or sell signals with the returns of a static strategy such as buy and hold. The former study focused on financial assets traded in India, and found that when the short-term moving average crossed above the long-term moving average, the prices generated positive net results. However, when transaction costs were considered, this profitability did not sustain itself. Ratner and Leal's study (Ratner and Leal 1999), which was broader and considered countries in Latin America and Asia, reached the same conclusion. The exceptions were the Taiwanese, Mexican, and Thai markets, whose profitability was maintained even after transaction costs were included.

For data regarding the United States of America (USA), Alexander (1961), Brock et al. (1992), and Fama and Blume (1966) found that if the transaction costs were not 
zero, the profitability gained by applying technical analysis was not significant. In comparison, Kuang et al. (2014) achieved an average annual return of approximately 30\% for emerging countries' stock markets. However, they considered that this profitability was not accurate, since it was the result of problems arising from prior manipulation of the data to discover ex-ante patterns.

In a study using data from Bangladesh, Mobarek et al. (2008) proposed that the accelerated growth of the capitalization level in that country was an investment opportunity. The research emphasized that Bangladesh was an emerging country that had undergone extreme structural economic changes in which the focus on agriculture was abandoned in favor of a strategy involving industrialization and the formation of new companies. The null hypothesis that the market is weakly efficient was rejected after verification.

These results showed the weakness of moving average techniques in predicting price behavior. They also suggested that if transaction costs are negligible, technical analysis becomes a viable alternative, indicating that under certain conditions the markets are not efficient. Treynor and Ferguson (1985) emphasized the importance of historical prices in forecasting price behavior as a complement to the role played by the information available to suppliers and claimants who are, above all, responsible for creating profit opportunities.

Shynkevich (2012) concluded that the profitability of technical analysis for portfolios holding small cap assets with less liquidity was greater than for portfolios holding large cap companies from the technology area. For this reason, it is especially relevant to analyze the returns of classic technical indicators for emerging markets where more small caps are expected, possibly because of policies used to stimulate industrial activity.

Recent empirical evidence for South Africa verified by Noakes and Rajaratnam (2014) suggested that the level of capitalization of traded assets in that country was inversely related to market inefficiency. Moreover, the authors suggested that the degree of market efficiency falls during periods of crisis, as during the financial crisis of 2008.

The research of Costa et al. (2015) analyzed the power of technical analysis indicators for the Brazilian asset market. The authors concluded that technical analysis has weak predictive power whether or not brokerage fees are considered. However, the use of crossing moving averages, simple or exponential, and Moving Average Convergence Divergence (MACD) provided a high probability of guaranteeing a return greater than the amount invested. In general, research indicated that it is natural for markets to become efficient, because they do not obtain significant returns from past price behavior. Thus, evidence for technical analysis in emerging markets suggested less efficiency in these countries, which might set up an attractive investment option for the foreign investor.

Sobreiro et al. (2016) obtained positive and above-average returns generated by the static buy and hold strategy for the short-term SMA crossing over the long-term SMA. However, although some combinations of short- and long-term SMAs were profitable for some countries, they did not provide sustained profitability for other emerging countries. Consequently, a more general conclusion could not be reached from the study. In general, buy and hold is a more profitable and risk-free alternative to an automated strategy for most emerging markets. 
It is worth mentioning that the approach of Sobreiro et al. (2016) does not explore the impact of transaction cost on a portfolio's return, which has a significant cooling effect on the performance of the trades, and is subject to currency rate volatility. With regard to this last aspect, it is worth noting that the authors' use of 10,000.00 local currency units as the initial value of the portfolio left the investments open to the effects of exchange rate fluctuations and inflation that often impact the currencies of emerging countries.

Concerning the influence of technical analysis on fundamental analysis, Almujamed et al. (2013, pp. 57-58) studied data for Kuwait. They concluded that investors check a firm's profitability before looking at the stock chart movements and stock price trends of the company. Furthermore, they asserted that fundamental analysis that uses a more recent series of prices, usually within five years, is employed more commonly by investors in developed markets, while emerging markets are considered inefficient.

According to Bettman et al. (2009, pp. 21-22), TA and FA are complementary, since models that combine the assumptions and elements of both analyses achieve higher profitability than models based on a single approach only. For their analysis of TA and FA, the authors ran linear regression models with explanatory variables from TA, e.g., trend and momentum indicators based on past prices. They also ran models using variables from FA, e.g., book value and earnings per share, and models using variables from both. Bettman's findings indicated that a model with independent variables from both approaches provided better performance based on statistics such as the Akaike information criterion (AIC) and likelihood ratio tests. The work of Wang et al. (2014, pp. 33) supported a similar conclusion, showing that the joint application of FA and TA reduced the risk of the investment.

Chong et al. (2010, pp. 237-238) set out to compare the performance of the traditional technical analysis indicators for the BRIC1. They concluded that the average profit in Russia surpassed the returns obtained in the other countries, and the evidence indicated that the Brazilian open market was the most efficient. The authors attributed these findings to the fact that the age of the market was directly related to efficiency. Therefore, they supported the view that markets become efficient over time. However, the costs associated with open market buy and sell transactions were not considered. Lo et al. (2000, pp. 1753-1764) demonstrated that technical analysis benefits from the automation provided by computerized trading systems, with emphasis on the identification of visual patterns in the asset price series.

Tharavanij et al. (2015, pp. 39-40) analyzed the performance of a wide variety of technical indicators for similar Asian emerging markets, such as Malaysia, Indonesia, Singapore, and Thailand. The analysis was conducted on a risk-adjusted basis, and accounted for brokerage fees. The authors found several levels of efficiency in the markets, but overall, TA strategies could not beat the buy and hold benchmark, and prices could not foster excess returns above the market average. These results indicated that similar characteristics did not lead to a single winning strategy.

\section{Method}

To meet the objectives of this paper, we developed a transaction model, called the automated trading system (ATS), that worked automatically based on classic technical 
analysis, especially the use of moving averages, to soften price series and identify trends. As described by Booth et al. (2014, p. 3651), automated trading systems perform trades autonomously, identifying investment opportunities based on artificial intelligence methods. The procedures that define the strategy used to generate trading signals can vary substantially. Technical indicators have found wide spread use for this purpose as a result of their extensive application by market practitioners.

Whatever the method used in a trading system, the base assumption is still the same: price predictions are based on past price data. According to Cervelló-Royo et al. (2015, p. 5963), this principle imposes an important challenge for individual investors and companies, because forecasts of future prices are subject to occasional unexpected fluctuations that do not depend on the historical behavior of the markets. Chen and Chen (2016, pp. 261-262) indicated that the stock market is subject to many changes in the underlying environment, such as variations in economic, political, and industrial conditions. According to the authors, finding the proper means for analysis is paramount for defining better or worse strategies for generating profits in the market.

Concerning the psychological aspects of the investors, Pring (2016, pp. 2-5) emphasized that TA reflects the concept that price trends depend on the attitudes of individuals, i.e., the mass psychology of the crowd. In this context, technical analysis relies on the assumption that herd behavior fluctuates between periods of fear or pessimism and times of confidence or optimism.

We chose to use the crossover of moving averages for the generation of buy and sell signals because this technique is employed extensively by financial market analysts, is based on graphical patterns of historical market prices (Alexander 1961; Reitz 2006), and allows for a comparatively simple approach to computational implementation. The algorithm for the generation of buy signals is based on the crossing of two series generated from the available quotations for the assets: the short-term moving average and the long-term moving average. For the analysis of the technical indicators, based on Ellis and Parbery (2005), we agreed that a buy signal would be issued when the short-term MA becomes bigger than the longterm MA, and a sales signal would be issued when the short-term MA becomes smaller than the long-term MA.

The study's data came from the daily closing quotations for 1454 assets traded on the BRICS stock exchanges: 236 assets from South Africa, 198 assets from Brazil, 65 assets from Russia, 755 assets from India, and 300 assets from China, as shown in Table 2. The data were taken from Bloomberg $\odot$ and included historical prices for 2569 assets. For computing purposes, we opted to choose the 300 most dynamic assets in the Chinese market.

Table 2 Information of countries

\begin{tabular}{lllll}
\hline Countries & Number of Stocks & Period & Exchange at 6/24/2016 & $\begin{array}{l}\text { Initial Capital at Local } \\
\text { Currency }\end{array}$ \\
\hline Brazil. & 198 & $2007-2016$ & 33,728 BRL/USD & 33,728 BRL \\
Russia. & 65 & $2007-2016$ & 65,676 RUB/USD & 656,760 RUB \\
India. & 755 & $2000-2016$ & 67,858 INR/USD & 678,580 INR \\
China. & 300 & $2000-2016$ & 66,155 CNY/USD & 661,550 CNY \\
South Africa. & 236 & $2000-2016$ & 150,876 ZAR/USD & 150,876 ZAR \\
\hline
\end{tabular}


Of the total assets of the database, some did not allow the generation of buy/sell signals, and therefore were excluded from the portfolio. Data for South Africa, China, and India corresponded to the period from 2000 to 2016. For Brazil and Russia, the period considered was from 2007 to 2016. For the transaction simulations, we used the closing prices per day.

Also, the simulations were carried out considering an application of US\$10,000.00 in local currency quoted on June 24, 2016 to normalize the investment from the perspective of an external investor. Returns obtained were compared with and without the inclusion of costs. Neither of these aspects were considered in Sobreiro et al. (2016), whose simulations were made with the initial application of 10,000.00 local currency units and without considering transaction costs. Similarly, costs were not considered in Chong et al. (2010).

For our research, we constructed a portfolio composed of a wide number of holdings. This approach allowed us to verify the average profitability gained through technical analysis for all assets traded in the stock market for each BRICS member country. Given these conditions, we considered an investor who was investing US\$10,000.00 in each asset of the country, converted at the exchange rate on June 24, 2016.

In the moving average system, a buy signal is generated when the short-term MA becomes greater than the long-term MA, indicating the start of an uptrend and the end of a downtrend. On the other hand, if the long-term MA becomes greater than the short-term MA, a sell signal is generated. This is one of the very basic principles agreed upon among chartists.

It is worth noting that three types of moving average crossovers were analyzed in our trading system: SMA-SMA, SMA-EMA, and EMA-EMA. In each class, we used groups of MA combinations, with the short-term MA ranging from 5 to 40 periods, and the long-term MA varying from 80 to 120 periods. Although the periods were arbitrary, the short-term MA reflected a time horizon of approximately 2 months, and the longterm MA a time horizon between 4 to 6 months. To perform the computational experiment, the algorithm was implemented in the software's programming language.

Since the short-term MA varied between 5 and 40 periods, and the long-term MA varied between 80 and 120 periods, we had 1.476 strategies for a single class of crossover. Thus, we had 4.428 strategies, and for each one, three simulations were made: without transaction costs, with brokerage costs of $2 \%$, and with brokerage costs of $5 \%$.

Since the purpose of the study was to formulate an automated model to investigate the profitability and efficiency of technical analysis in emerging markets, the return obtained in local currency was converted into dollars according to the exchange rate of the investment's initial date. This procedure eliminated the impact of any nominal exchange rate and inflation fluctuations on transactions.

We elaborated and compiled the algorithm in the R software, which allowed handling a large mass of data in an uncomplicated way. In general, the execution flow of the automated trading system can be summarized by the pseudo-code presented in Algorithm 1.

The automated trading system had a graphical user interface (shown in Fig. 1), also elaborated in $\mathrm{R}$ to facilitate the collection of input data that came from tables containing the closing price history of traded assets and the set of parameters. The latter included the specification of the moving average type, the range of each MA, and the initial capital to be applied. 


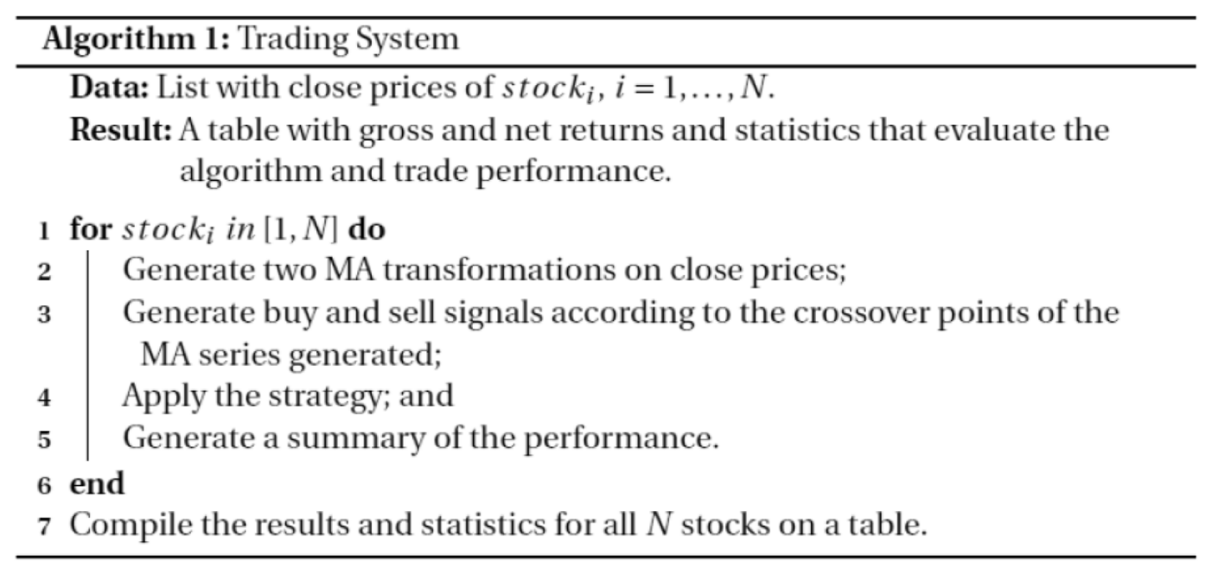

\section{Results}

The use of the automated trading system generated a summary of the performance of each asset in each country. Concerning the profitability of the operations, the proportion of the assets of each country was identified for each strategy. Our approach was able to surpass the profit obtained through buy and hold, which is a lower risk strategy. Buy and hold is a long-term investment approach in which the investor creates a

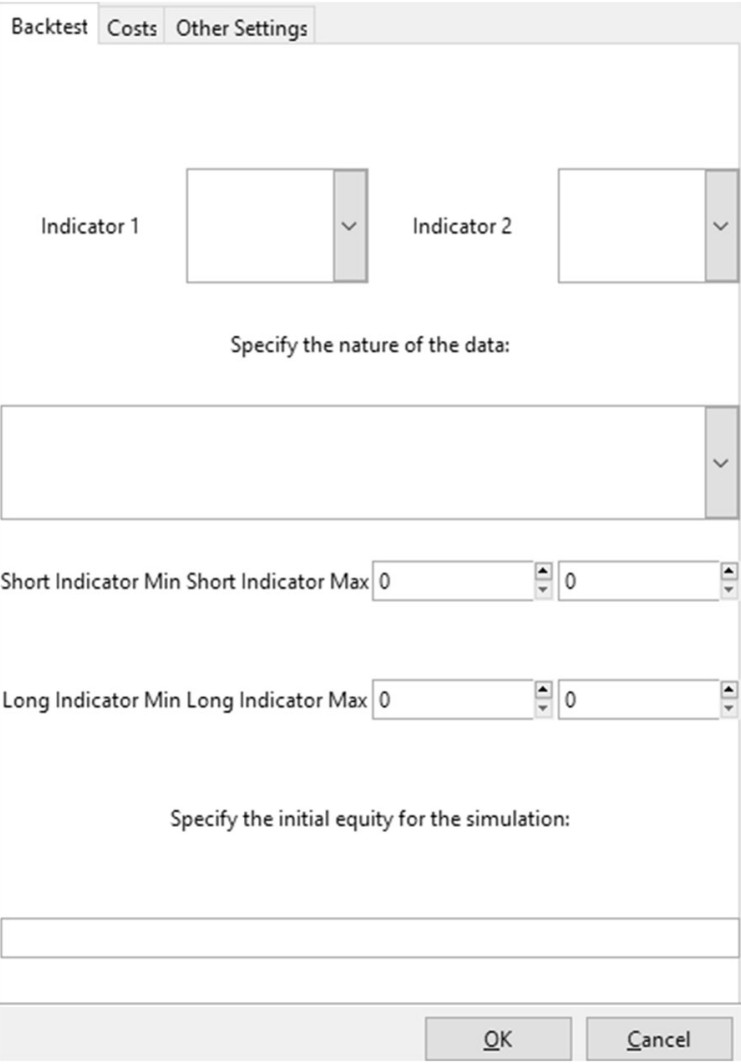

Fig. 1 Interface of Automated Trading System 
portfolio of assets, and sells only when the valuation of the assets is considered satisfactory, providing above-market average returns.

Table 3 shows the average returns per country when buy and hold was implemented. In short, we applied the buy and hold strategy for each asset of the same country, and we extracted the average profitability of the operations for each country.

The data available in Table 2 supports Table 4, which shows the proportion of assets in each country that surpassed the average buy and hold return for the same country. We chose to compare the returns of each asset obtained by the automated trading system with the average market return of the risk-free strategy to identify groups of assets that offered good, consistent performance and were issued by dynamic companies in the market.

In general, dynamic strategies for the purchase and sale of assets are studied to determine whether it is possible to obtain above-market average returns in the short term. According to Table 4, a tiny group of assets surpassed the buy and hold returns using the automated trading system. However, the main conclusion here is that there was a group of assets in each country that could outperform the passive buying strategy.

As shown in Fig. 2, the average return was very high in India and Russia. Because their stock markets are younger, efficiency may be related to market maturity, indicating that technical analysis performs well and sustains the results of Chong et al. (2010). However, this argument could be a topic for further study. Moreover, in these same markets, the increase in transaction costs shifted significantly the range of the shortterm MAs that were better, as presented by Tables 5,6 , and 7 .

Results for India and Russia indicated higher returns, but our study did not focus on potential explanations for the different results among the countries. TA explores information from past data only, without consideration of macro or micro elements that could explain the future price behavior of specific stocks. Consequently, the results of the analysis indicated potential violations of the weak form of market efficiency, but could not be used to explain potential fundamental rationales for the profitability of trading strategies.

For the South African market, one of the most consolidated of the samples, the most attractive returns were stable. For the three categories of MA crossovers, and for all simulated types of cost, the short-term MA crossover at the interval [37; 40] with the long-term MA of the range $[116 ; 120]$ proved to be profitable in all simulations. Thus, more efficient markets showed more conservative, but more stable, returns.

Table 3 Buy and hold results

\begin{tabular}{llll}
\hline Countries & $\begin{array}{l}\text { Initial Capital at } \\
\text { Local Currency }\end{array}$ & $\begin{array}{l}\text { Average Buy and Hold Result } \\
\text { (Local Currency) }\end{array}$ & $\begin{array}{l}\text { Average Buy and Hold } \\
\text { Result (Dollars) }\end{array}$ \\
\hline Brazil. & 33,728 BRL & $153,936.90$ BRL & $45,640.48$ USD \\
Russia. & 656,760 RUB & $4,066,074$ RUB & $61,911.11$ USD \\
India. & 678,580 INR & $23,877,054$ INR & $351,867.93$ USD \\
China. & 661,550 CNY & $3,999,462$ CNY & $60,455.93$ USD \\
South Africa. & 150,876 ZAR & $1,559,474$ ZAR & $103,361.30$ USD \\
\hline
\end{tabular}


Table 4 Percentage of better results than the buy and hold

\begin{tabular}{llll}
\hline Countries & SMA vs SMA & EMA vs EMA & SMA vs EMA \\
\hline Brazil. & $14.34 \%$ & $15.08 \%$ & $16.25 \%$ \\
Russia. & $11.00 \%$ & $9.20 \%$ & $9.28 \%$ \\
India. & $13.83 \%$ & $14.12 \%$ & $13.47 \%$ \\
China. & $19.46 \%$ & $20.17 \%$ & $19.45 \%$ \\
South Africa. & $9.79 \%$ & $11.81 \%$ & $12.64 \%$ \\
\hline
\end{tabular}

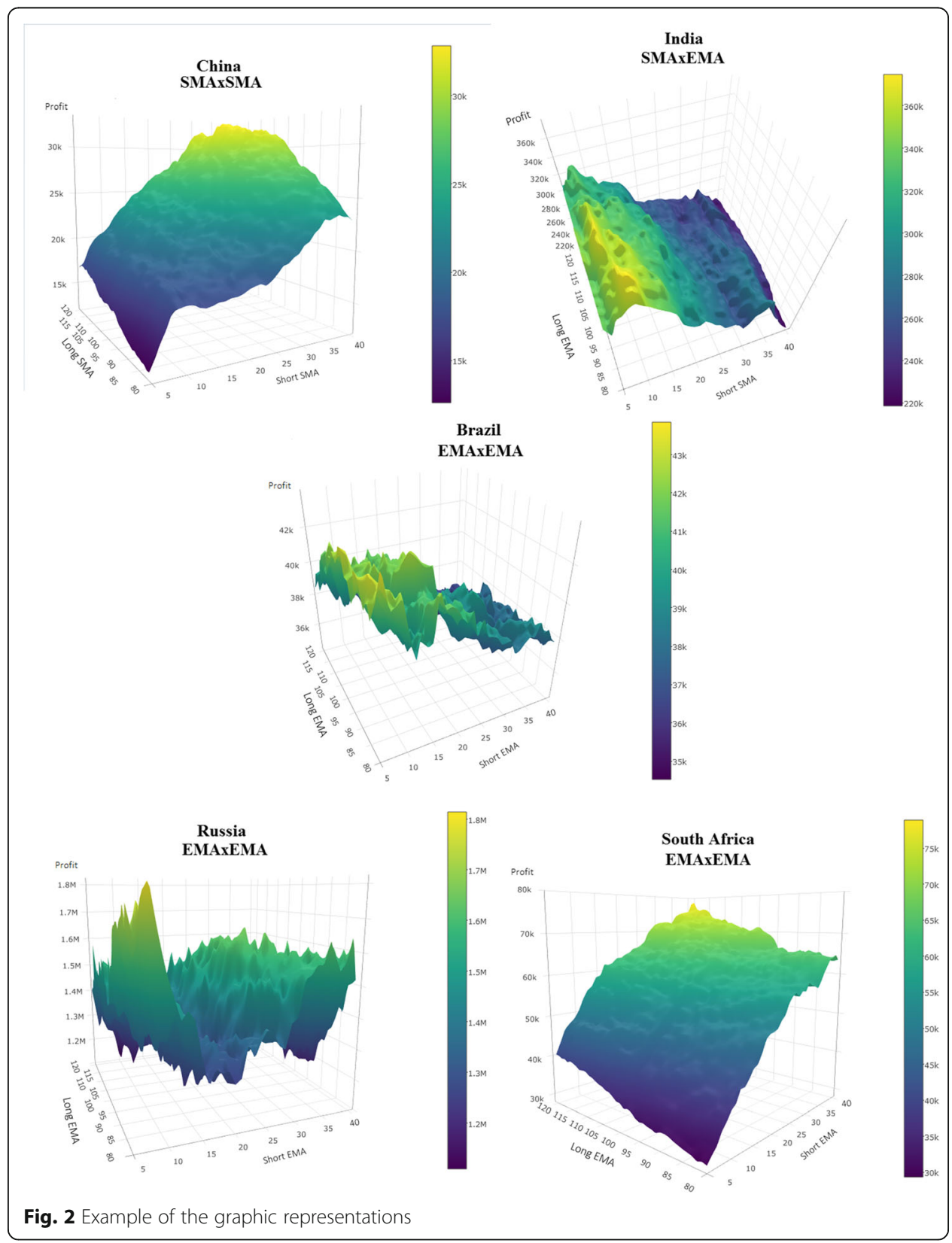


Table 5 Best pairs of Moving Averages considering the combination SMA vs SMA

\begin{tabular}{llll}
\hline Countries & Brokerage & & \\
\cline { 2 - 4 } & No Transaction Costs & $0.50 \%$ & $2 \%$ \\
\hline Brazil. & Short: $[5 ; 15]$ & Short: $[10 ; 16]$ & Short: $[10 ; 24]$ \\
& Long: $[80 ; 117]$ & Long: $[80 ; 115]$ & Long: $[90 ; 110]$ \\
Russia. & Short: $[5 ; 8]$ & Short: $[5 ; 8]$ & Short: $[20 ; 28]$ \\
& Long: $[80 ; 85]$ & Long: $[80 ; 85]$ & Long: [90; 98] \\
India. & Short: $[5 ; 10]$ & Short: $[5 ; 15]$ & Short: $[30 ; 37]$ \\
& Long: $[80 ; 105]$ & Long: $[80 ; 115]$ & Long: $[110 ; 120]$ \\
China. & Short: $[32 ; 40]$ & Short: $[31 ; 40]$ & Short: $[31 ; 40]$ \\
& Long: $[90 ; 112]$ & Long: $[99 ; 115]$ & Long: $[102 ; 120]$ \\
South Africa. & Short: $[15 ; 17],[37 ; 40]$ & Short: $[36 ; 40]$ & Short: $[37 ; 40]$ \\
& Long: $[115 ; 120]$ & Long: $[116 ; 120]$ & Long: $[116 ; 120]$ \\
\hline
\end{tabular}

\section{Conclusion}

This paper investigated the efficiency and profitability of applying technical analysis to the stock markets of BRICS member countries. We analyzed whether investors could obtain above-average returns, as suggested by the recent research of Stanković et al. (2015) and others. For this research, we assembled a comprehensive portfolio of stocks from the BRICS countries that contained all the assets traded in the markets of each BRICS member. We developed an automated trading system that simulated transactions in this portfolio using technical analysis techniques.

While this system was developed carefully, the study had some limitations. For example, we assumed that the stocks had high liquidity, and that transactions could be traded at specific market prices. Nonetheless, the results indicated that our automated trading system, using technical analysis, could surpass the profitability of a buy and hold strategy for a small portion of the traded assets, calculated by country. Although small, this portion presented returns well above the amount invested, because the gains were from assets related to dynamic companies in the stock market.

Table 6 Best pairs of Moving Averages considering the combination EMA vs EMA

\begin{tabular}{|c|c|c|c|}
\hline \multirow[t]{2}{*}{ Countries } & \multicolumn{3}{|l|}{ Brokerage } \\
\hline & No Transaction Costs & $0.50 \%$ & $2 \%$ \\
\hline \multirow[t]{2}{*}{ Brazil. } & Short: $[5 ; 20]$ & Short: $[11 ; 24]$ & Short: $[20 ; 32]$ \\
\hline & Long: [80; 105] & Long: [80; 110] & Long: [80; 112] \\
\hline \multirow[t]{2}{*}{ Russia. } & Short: $[5 ; 8],[11 ; 14]$ & Short: [19;20] & Short: [26; 28] \\
\hline & Short: $[5 ; 8],[11 ; 14]$ & Long: [80; 82] & Long: [91; 92] \\
\hline \multirow[t]{2}{*}{ India. } & Short: $[5 ; 13]$ & Short: $[5 ; 16]$ & Short: $[15 ; 20],[30 ; 34]$ \\
\hline & Long: [80; 120] & Long: [80; 96] & Long: [80; 120] \\
\hline \multirow[t]{2}{*}{ China. } & Short: [5; 7], [32; 34] & Short: $[33 ; 38]$ & Short: [33; 40] \\
\hline & Long: [80; 85] & Long: [80; 120] & Long: [90; 120] \\
\hline \multirow[t]{2}{*}{ South Africa. } & Short: $[36 ; 40]$ & Short: $[36 ; 40]$ & Short: $[35 ; 40]$ \\
\hline & Long: [96; 120] & Long: [96; 120] & Long: [97; 120] \\
\hline
\end{tabular}


Table 7 Best pairs of Moving Averages considering the combination SMA vs EMA

\begin{tabular}{|c|c|c|c|}
\hline \multirow[t]{2}{*}{ Countries } & \multicolumn{3}{|l|}{ Brokerage } \\
\hline & No Transaction Costs & $0.50 \%$ & $2 \%$ \\
\hline \multirow[t]{2}{*}{ Brazil. } & Short: $[5 ; 10]$ & Short: $[15 ; 20]$ & Short: [16; 22] \\
\hline & Long: [80; 100] & Long: [80; 106] & Long: [80; 107] \\
\hline \multirow[t]{2}{*}{ Russia. } & Short: $[5 ; 8]$ & Short: $[31 ; 40]$ & Short: $[35 ; 40]$ \\
\hline & Long: [80; 83] & Long: [80; 86] & Long: [112; 120] \\
\hline \multirow[t]{2}{*}{ India. } & Short: $[5 ; 9]$ & Short: $[5 ; 10]$ & Short: [33; 40] \\
\hline & Long: [80; 100] & Long: [80; 96] & Long: [80; 98] \\
\hline \multirow[t]{2}{*}{ China. } & Short: $[5 ; 7]$ & Short: $[35 ; 40]$ & Short: $[33 ; 40]$ \\
\hline & Long: [80; 83] & Long: [100; 120] & Long: [100; 120] \\
\hline \multirow[t]{2}{*}{ South Africa. } & Short: [33; 40] & Short: [33; 40] & Short: [35; 40] \\
\hline & Long: [100; 120] & Long: [110; 120] & Long: [110; 120] \\
\hline
\end{tabular}

Our findings demonstrated the feasibility and value of applying technical analysis in this context. On average, the returns obtained using TA surpassed the value invested. Since some assets performed very well, they covered the losses incurred by other low-performing assets. However, few combinations of moving averages were able to outperform the returns from a buy and hold strategy.

In addition, our study suggests that technical analysis and fundamental analysis can complement each other. We proposed that TA could foster the search for groups of companies listed on the stock market that have a dynamic level of capitalization and present a strong profit opportunity for investors. For this portion of our work, we analyzed combinations of moving averages that were persistently profitable within the BRICS markets. Table 4 indicates that some assets could surpass the returns obtained by a risk-free strategy. Tables 5, 6, and 7 display pairs of MAs with a higher density of positive results, i.e., combinations of MAs in which the returns obtained by good performing assets raised the average return, even though there were many low-performing assets.

This study also contributed to the evidence that market age is directly related to market efficiency, as suggested by Chong et al. (2010). Thus, the assumption that markets become more efficient over time was supported, even when the automated trading system included transaction costs. This result was linked to the fact that the Brazilian stock market, the second oldest within the sample, generated one of the lowest average returns. This evidence suggests that the markets become more efficient as time goes by, implying that for older stock markets, historical prices may contain less information that can be used to generate above-average returns. However, since there is not a definitive a priori hypothesis that links stock market age and market efficiency, the outcome of the study cannot support this relationship decisively.

Our findings indicated further that even though the sample countries are classified as emerging, and they are part of the same economic group, their respective stock markets are not necessarily close to each other in terms of their behavior. This conclusion is based on the difficulty identifying a single combination of moving averages common to all the countries analyzed that could generate a consistent return. Moreover, the average return obtained diverged considerably among the BRICS stock exchanges, showing 
that the efficiency of a market and the opportunities for profitability are more closely related to the age of the market than to whether the country is emerging.

Our study suggested that even though the BRICS markets may share similar characteristics, the trading systems lead to very heterogeneous results. In some countries, trading based on moving averages could not exceed the buy and hold strategy. Therefore, there is no clear pattern in the historical data that could be used generally across the markets. Although results support that the weak form of the efficient market hypothesis could be rejected, the trading strategy did not lead universally to better results than the gains generated by the buy and hold strategy.

Based on this study, we can point out strategies that result in above-average profitability, raising questions about the EMH in emerging markets. A question that remains to be answered, however, is why some combinations of moving averages perform better than others. For example, in South Africa the most profitable short-term MAs belonged to a very specific range. Another area for future research is analysis of the role played by small cap assets in the performance of moving average strategies in emerging markets.

Acknowledgements

Not applicable.

Funding

Not applicable.

Availability of data and materials

Not applicable.

\section{Authors' contributions}

All authors participated in the development of the research. MJSS, DGFR and MGP conducted the study and the results were discussed initially with VAS and HK. Following the all authors developed the initial version of the manuscript. Then, VAS revised and improvement in the paper and its graphical content. Finally, all authors read and approved the final manuscript.

\section{Authors' information}

Matheus José Silva de Souza holds a Bachelor's degree in Economics from the University of Brasília. Danilo Guimarães Franco Ramos holds a Bachelor's degree in Statistic from the University of Brasília. Marina Garcia Pena holds a Bachelor's degree in Statistic from the University of Brasília.

Vinicius Amorim Sobreiro is an Adjunct Professor at the Department of Management at the University of Brasília. He holds a PhD in Production Engineering. He received his Bachelor's degree in Economics from the Antônio Eufrásio Toledo College.

Herbert Kimura is a Full Professor at the Department of Management at the University of Brasilia. He holds a PhD in Statistic. He received his Bachelor's degree in Electronic Engineering from the Institute of Aeronautical Technology.

\section{Competing interests}

All authors declare that they have no competing interests.

\section{Author details \\ ${ }^{1}$ Department of Economics, University of Brasília, Federal District, Brazil. ${ }^{2}$ Department of Management, University of} Brasília, Federal District, Brazil.

Received: 25 May 2017 Accepted: 8 February 2018

Published online: 24 February 2018

\section{References}

Alexander SS (1961) Price movements in speculative markets: Trends or random walks. Industrial Management Review $1: 7-26$

Allen H, Taylor MP (1990) Charts, Noise and Fundamentals in the London Foreign Exchange Market. Econ J 100(400): 49-49

Almujamed HI, Fifield S, Power D (2013) An Investigation of the Role of Technical Analysis in Kuwait. Qualitative Research in Financial Markets 5(1):43-64

António Silva NH, Neves R (2015) A hybrid approach to portfolio composition based on fundamental and technical indicators. Expert Syst Appl 42(4):2036-2048

Appel G (2005) Technical Analysis: Power Tools for Active Investors. Prentice Hall Publishing, NJ 
Bessembinder H, Chan K (1995) The profitability of technical trading rules in the Asian stock markets. Pac Basin Financ J 3(2-3):257-284

Bettman JL, Sault SJ, Schultz EL (2009) Fundamental and technical analysis: Substitutes or complements? Account Finance 49(1):21-36

Booth A, Gerding E, McGroarty F (2014) Automated trading with performance weighted random forests and seasonality. Expert Syst Appl 41(8):3651-3661

Brock W, Lakonishok J, Lebaron B (1992) Simple Technical Trading Rules and the Stochastic Properties of Stock Returns. J Financ 47(5):1731-1764

Cervelló-Royo R, Guijarro F, Michniuk K (2015) Stock market trading rule based on pattern recognition and technical analysis: Forecasting the DJIA index with intraday data. Expert Syst Appl 42(14):5963-5975

Chang EJ, Lima EJA, Tabak BM (2004) Testing for Predictability in Emerging Equity Markets. Emerg Mark Rev 5(3): 295-316

Chen TL, Chen FY (2016) An intelligent pattern recognition model for supporting investment decisions in stock market. Inf Sci 346-347(1):261-274

Chong TTL, Cheng SHS, Wong ENY (2010) A Comparison of Stock Market Efficiency of the BRIC Countries. Technol Invest 01(04):235-238

Costa TRCC, Nazário RT, GSZ B, Sobreiro VA, Kimura H (2015) Trading System Based on the Use of Technical Analysis: A Computational Experiment. Journal of Behavioral and Experimental Finance 6(1):42-55

Ellis CA, Parbery SA (2005) Is Smarter Better? A Comparison of Adaptive, and Simple Moving Average Trading Strategies. Res Int Bus Financ 19(3):399-411

Errunza VR, Losq E (1985) The Behavior of Stock Prices on LDC Markets. J Bank Financ 9(4):561-575

Fama EF (1970) Efficient capital markets: A review of theory and empirical work. J Financ 25(2):383-417

Fama EF, Blume ME (1966) Filter Rules and Stock-Market Trading. J Bus 39(S1):226-226

Frankel JA, Froot KA (1986) Understanding the US Dollar in the Eighties: The Expectations of Chartists and Fundamentalists. Econ Rec 62(1):24-38

Gerritsen DF (2016) Are chartists artists? The determinants and profitability of recommendations based on technical analysis. Int Rev Financ Anal 47:179-196

Gunasekarage A, Power DM (2001) The profitability of moving average trading rules in South Asian stock markets. Emerg Mark Rev 2(1):17-33

Harvey CR (1995) Predictable Risk and Returns in Emerging Markets. Rev Financ Stud 8(3):773-816

Jegadeesh N (2000) Discussion. J Financ 55(4):1765-1770

Jensen MC (1978) Some Anomalous Evidence Regarding Market Efficiency. J Financ Econ 6(2-3):95-101

Keynes JM (1936) The General Theory of Employment, Interest and Money, Chapter 12: The State of Long-Term Expectation. Macmillan, London

Kuang P, Schröder M, Wang Q (2014) Illusory Profitability of Technical Analysis in Emerging Foreign Exchange Markets. Int J Forecast 30(2):192-205

Lam M (2004) Neural network techniques for financial performance prediction: integrating fundamental and technical analysis. Decis Support Syst 37(4):567-581

Lo AW, Mackinlay AC (1987) Stock Market Prices Do Not Follow Random Walks: Evidence From A Simple Specification Test. Tech. rep.

Lo AW, Mamaysky H, Wang J (2000) Foundations of Technical Analysis: Computational Algorithms, Statistical Inference, and Empirical Implementation. J Financ 55(4):1705-1765

Lui YH, Mole D (1998) The Use of Fundamental and Technical Analyses by Foreign Exchange Dealers: Hong Kong Evidence. J Int Money Financ 17(3):535-545

Malkiel BG, Fama EF (1970) Efficient Capital Markets: A Review of Theory and Empirical Work Ast. J Financ 25(2):383-417

Mitra SK (2011) How Rewarding is Technical Analysis in the Indian Stock Market? Quantitative Finance 11(2):287-297

Mobarek A, Mollah AS, Bhuyan R (2008) Market Efficiency in Emerging Stock Market: Evidence From Bangladesh. Journal of Emerging Market Finance 7(1):17-41

Mozumder N, Vita GD, Kyaw SK, Larkin C (2015) Volatility spillover between stock prices and exchange rates: New evidence across the recent financial crisis period. Economic Issues 20(1):43-64

Mukherjee P, Roy M (2016) What Drives the Stock Market Return in India? An Exploration with Dynamic Factor Model. Journal of Emerging Market Finance 15(1):119-145

Murphy JJ (1999) Technical Analysis of the Financial Markets. New York Institute of Finance, Paramus

Naresha G, Vasudevan G, Mahalakshmi S, Thiyagarajan S (2017) Spillover effect of US dollar on the stock indices of BRICS. Res Int Bus Financ Article in press

Nison S (1991) Japanese Candlestick Charting Techniques. New York Institute of Finance

Noakes MA, Rajaratnam K (2014) Testing Market Efficiency on the Johannesburg Stock Exchange Using the Overlapping Serial Test. Ann Oper Res 243(1-2):273-300

Park CH, Irwin SH (2007) What do We Know About the Profitability of Technical Analysis? J Econ Surv 21(4):786-826

Pring MJ (2016) Technical Analysis Explained Fifth Edition The Successful Investor's Guide to Spotting Investment Trends and Turning Points, vol 1, 5th edn. McGraw-Hill

Ratner M, Leal RP (1999) Tests of Technical Trading Strategies in the Emerging Equity Markets of Latin America and Asia. J Bank Financ 23(12):1887-1905

Reitz S (2006) On the Predictive Content of Technical Analysis. The North American Journal of Economics and Finance 17(2):121-137

Sharma JL, Kennedy RE (1977) A Comparative Analysis of Stock Price Behavior on the Bombay, London, and New York Stock Exchanges. The Journal of Financial and Quantitative Analysis 12(3):391-391

Shiller RJ (1989) Market Volatility. The M.I.T. Press, Cambridge

Shynkevich A (2012) Performance of Technical Analysis in Growth and Small Cap Segments of the US Equity Market. J Bank Financ 36(1):193-208 
Sobreiro VA, Costa TRCC, Nazário RTF, e Silva JL, Moreira EA, MCL F, Kimura H, JCA Z (2016) The Profitability of Moving Average Trading Rules in BRICS and Emerging Stock Markets. The North American Journal of Economics and Finance 38(1):86-101

Stanković J, Marković I, Stojanović M (2015) Investment Strategy Optimization Using Technical Analysis and Predictive Modeling in Emerging Markets. Procedia Economics and Finance 19(1):51-62

Tharavanij P, Siraprapasiri V, Rajchamaha K (2015) Performance of technical trading rules: Evidence from Southeast Asian stock markets. SpringerPlus 4(1):1-40

Treynor JL, Ferguson R (1985) In Defense of Technical Analysis. J Financ 40(3):757-773

Urrutia JL (1995) Tests of Random Walk and Market Efficiency for Latin American Emerging Equity Markets. J Financ Res 18(3):299-309

Vandewalle N, Ausloos M, Boveroux P (1999) The Moving Averages Demystified. Physica A: Statistical Mechanics and Its Applications 269(1):170-176

Wang YC, Yu J, Wen SY (2014) Does Fundamental and Technical Analysis Reduce Investment Risk for Growth Stock? An Analysis of Taiwan Stock Market. International Business Research 7(11):1-11

Zhu Y, Zhou G (2009) Technical Analysis: An Asset Allocation Perspective on the Use of Moving Averages. J Financ Econ 92(3):519-544

Submit your manuscript to a SpringerOpen ${ }^{\circ}$ journal and benefit from:

- Convenient online submission

- Rigorous peer review

- Open access: articles freely available online

- High visibility within the field

- Retaining the copyright to your article

Submit your next manuscript at $\gg$ springeropen.com 